\title{
Third stage of labour: expectant versus active management-a comparative study in local low risk population
}

\author{
Kavita A. Chandnani ${ }^{1}$, Deepti D. Sharma ${ }^{2 *}$ \\ ${ }^{1}$ Department of Obstetrics and Gynecology, SBKSMIRC, Dhiraj general hospital, Vadodara, Gujarat, India \\ ${ }^{2}$ Department of Obstetrics and Gynecology, GMERS Medical College, Gotri, Vadodara, India
}

Received: 24 November 2018

Accepted: 29 December 2018

*Correspondence:

Dr. Deepti D. Sharma,

E-mail: deeptisharma_403@yahoo.co.in

Copyright: (c) the author(s), publisher and licensee Medip Academy. This is an open-access article distributed under the terms of the Creative Commons Attribution Non-Commercial License, which permits unrestricted non-commercial use, distribution, and reproduction in any medium, provided the original work is properly cited.

\section{ABSTRACT}

Background: Postpartum haemorrhage (PPH) is the leading cause of maternal mortality, accounting for about $35 \%$ of all maternal deaths. These deaths have a major impact on the lives and health of the families affected. Thus, anticipation as well as proper management of $3^{\text {rd }}$ stage of labour is mandatory. The objective of this study was to compare expectant and active management of third stage of labour in preventing post-partum blood loss and having impact on prevention of maternal mortality in local population. Advantages and disadvantages of both techniques might be over estimated.

Methods: Prospective comparative study carried out in Obstetrics and Gynecology department of SBKSMIRC (Shrimati Bhikhiben Kanjibhai Shah Medical Institute and Research Centre), Dhiraj general hospital, comprising of 200 laboring women admitted directly or from OPD to labour room for expected vaginal delivery. They were randomly allocated to group A (expectant management) and group B (active management). Labour progress was charted on partograph and interventions recorded. Statistical analysis of data was done after compiling and tabulation of data. Mean \pm SD for descriptive variables were calculated and appropriate statistical tests applied to determine significance.

Results: Average PPBL (post-partum blood loss) was $360.5 \mathrm{ml}$ in group A as compared to $290.6 \mathrm{ml}$ in group B. 12 patients in group A had blood loss more than $500 \mathrm{ml}$ while none in group B. $66 \%$ cases in group B had duration of third stage of labour less than 5 min as compared to only $22 \%$ in group A. the mean duration of third stage was 13.46 \pm 8.3 in group A while 5.32 \pm 3.05 in group B. these differences were statistically significant.

Conclusions: Active management of the third stage of labour is associated with less blood loss as well as a shorter duration of third stage compared with expectant management. It is reasonable to advocate this regime.

Keywords: Active management of the third stage of labour (AMTSL), Expectant management, Postpartum hemorrhage, Third stage of labour

\section{INTRODUCTION}

WHO facts state that everyday approximately 830 women die from preventable causes related to pregnancy and childbirth. The main direct causes of maternal death include postpartum-haemorrhage (PPH), sepsis eclampsia, unsafe abortion, and obstructed labour. ${ }^{1}$
Severe bleeding after childbirth (postpartum haemorrhage) being most common worldwide, accounts for at least one quarter of all maternal deaths. ${ }^{2}$ The risk of maternal mortality from PPH is 1 in 1000 deliveries in the developing countries and most of them (about 99\%) occur in low and middle income countries compared with only $1 \%$ in industrialized nation. ${ }^{3}$ Every year about 14 
million women around the world suffer from PPH. ${ }^{4}$ Thus, adequate management of third stage of labour becomes critical to reduce this burden.

According to the World Health Organization, normal blood loss during the third stage of labour is $500 \mathrm{ml}$ and time duration $\leq 30$ minutes. ${ }^{5}$ In low-income countries, where severe anaemia is prevalent, blood loss of $500 \mathrm{ml}$ after delivery can be detrimental. ${ }^{6}$ To reduce blood loss after delivery, the WHO, since 2007, recommends the Active Management of the Third Stage of Labour (AMTSL) be offered to all women delivering with skilled attendants (WHO 2007). ${ }^{7,8}$ According to WHO recommendations, there are Three important steps in AMTSL which include; uterotonics agents, preferably oxytocin 10uIM, immediately after the delivery of the baby, controlled cord traction (CCT) for delivery of the placenta, massage of uterine fundus after delivery of placenta. While in expectant management there is no use of prophylactic uterotonic agent, no cord clamping until pulsation cease and delivery of placenta by maternal effort and gravity rather than cord traction and no routine use of uterine massage until the uterus is atonic. ${ }^{9}$ As Postpartum haemorrhage is difficult to anticipate, predisposing factors should be kept in mind like distended uterus, prolonged labour, previous history of $\mathrm{PPH}$, high parity, obesity, advanced age etc. these are independent variables that can affect amount of blood loss post-partum. Extensive work has been done internationally to compare active vs. expectant management of third stage of labour. Although active management is precisely described, it is not always strictly applied, and the one which applied is rather nonspecifically referred to as the 'mixed' management, comprising the physiologic protocol diluted with one or two constituents of an active management. ${ }^{10} \mathrm{~A}$ trial from 14 European countries demonstrated the third stage of labour management to have significant international as well as national variations. ${ }^{11}$ Though international bodies as WHO, International federation of Gynaecologists and Obstetricians and the International Confederations of Midwives recommend AMTSL in all vaginal deliveries to prevent $\mathrm{PPH}$, the value of implementing all components of AMTSL in healthy women has not yet been established worldwide. ${ }^{12-15}$ In India, it is recommended that all women giving birth vaginally be given an intramuscular IU oxytocin immediately after birth. ${ }^{10}$ Thus, the study aimed at comparing the expectant and active management of third stage of labour in preventing blood loss by affecting the duration of third stage of labour.

\section{METHODS}

This was a prospective comparative study conducted at the department of obstetrics and gynecology at SBKSMIRC (Shrimati Bhikhiben Kanjibhai Shah Medical Institute and research Centre), Dhiraj general hospital, Baroda, from May 2012 to May 2013. Total of 200 antenatal women admitted in labour room directly or from outpatient department for vaginal delivery fulfilling the criteria were included in the study. They were randomly assigned to either active or expectant management by means of a chit in a sealed envelope kept under custody of observer (resident doctor). Informed written consent of patients and relatives was taken. 100 women each were allocated to expectant $(n=100$, Group A) and active $(n=100$, Group B) management of third stage of labour.

\section{Inclusion criteria}

- Normal non- complicated singleton pregnancies in the age group 19-35yrs with gestational age 36-42 weeks, vertex presentation without known high risks for PPH.

\section{Exclusion criteria}

- Known risks for PPH e.g., ante partum hemorrhage, chorioamnionitis, uterine over distension (macrosomia baby, polyhydramnios, multiple gestation), prolonged labour, pre-eclampsia previous history of C-section, intrauterine fetal death, multipara (>3) instrumental delivery, coagulation abnormalities, severe anemia and those having any medical disorders were excluded from the study.

The staff of labour ward was carefully informed about the respective components of active and expectant management of third stage of labour

\section{Active management of third stage comprised of}

- Administration of a prophylactic 10IU oxytocin intramuscular soon after baby birth.

- Immediate clamping of cord followed Controlled cord traction to deliver the placenta.

- Uterine massage after delivery of placenta.

\section{Expectant management comprised of}

- Waiting for signs of placental separation and allowing placenta to deliver spontaneously or with aid of gravity.

- Cord clamping after cessation of pulsations.

- Uterotonics if atony of uterus evident.

Data was collected as regards to age, parity, menstrual history, obstetrics history, and different parameters of labour and fetal outcome. Routine antenatal investigations were carried out. Pre-delivery vitals of the mother were noted, which included pulse and blood pressure. Constant monitoring of the labour was done and portogram was charted.

Time required for the second and third stage of labour was noted with a stop watch. Post-partum blood loss was measured by placing plastic $\mathrm{V}$ shaped drape beneath the perineum of the patient to collect the blood which was 
later transferred to a calibrated measuring flask. ${ }^{16-17}$ Postdelivery vitals were noted.

Haemoglobin was done on admission in labour room and postnatally after 24 hours in every patient. Patients developing PPH and retained placenta were managed according to the guidelines provided by WHO.

\section{Statistical analysis}

Data was compiled tabulated and analysed using SPSS vn15. Chi square test was applied with $p$ value of $<0.05$ considered as significant. Mean and standard deviation was calculated for descriptive statistics.

Outcome variables studied were amount of blood loss in third stage, duration of third stage and maternal vital parameters and fall in $\mathrm{Hb}$ levels.

Secondary outcomes included need for transfusions, additional uterotonics and incidence of retained placenta.

\section{RESULTS}

Demographic variables of the study population. Average age was comparable in both the groups, being $26 \pm 4.3$ years in group $A$ and $26 \pm 4$.7years in group B (Table 1).

Average gestational age in group A was 38 weeks and in group B was 39 weeks. Majority of the patients belonged to middle socioeconomic class and were housewives as it could have impact on antenatal care, most of them being booked cases.

Table 1: Demographic characteristics of study population.

\begin{tabular}{|c|c|c|}
\hline Characteristics & Group A & Group B \\
\hline Age, Mean (SD) & $26(4.3)$ & $26(4.7)$ \\
\hline \multicolumn{3}{|l|}{ Parity n (\%) } \\
\hline Nulliparous & $24(24)$ & $24(24)$ \\
\hline Primipara & $40(40)$ & $36(36)$ \\
\hline Second Para & $26(26)$ & $32(32)$ \\
\hline Third Para & $10(10)$ & $8(8)$ \\
\hline $\begin{array}{l}\text { Gestational age, average } \\
\text { weeks }\end{array}$ & 38.6 & 39 \\
\hline \multicolumn{3}{|l|}{ Booking status (n) } \\
\hline Booked & 90 & 94 \\
\hline unbooked & 10 & 06 \\
\hline $\begin{array}{l}\mathrm{Hb} \text { at enrollment }(\mathrm{gm} / \mathrm{dl}) \\
\text { Mean (SD) }\end{array}$ & $10.77 \pm 1.25$ & $10.21 \pm 1.03$ \\
\hline \multicolumn{3}{|l|}{ Outcome of pregnancy } \\
\hline $\begin{array}{l}\text { Fetal weight }(\mathrm{kg}) \text {, mean } \\
\text { (SD) }\end{array}$ & $2.76 \pm 0.23$ & $2.97 \pm 0.22$ \\
\hline Episiotomy (n) & 18 & 20 \\
\hline Perineal tears $(\mathrm{n})$ & 12 & 6 \\
\hline $\begin{array}{l}\text { Duration of second stage } \\
\text { of labour ( } \mathrm{min}) \text {, average }\end{array}$ & 23.12 & 20.3 \\
\hline
\end{tabular}

There were no statistically significant differences in prepartum haemoglobin levels (10.7, group A: 10.2, group B). The progress of labour was charted on portogram.

Comparable number of patients with respect to parity formed the two groups thus minimizing the probability of influence of multipara uterus on incidence of PPH and hence amount of blood loss.

Incidence of episiotomy was comparable in both groups however there were 12 cases who had perineal tears in group A as compared only 6 in groups B though the difference was statistically insignificant.

This was similar to the study conducted by Jangsten et al. ${ }^{18}$ Episiotomy and perineal tears were found to be independent risk factors for total amount of blood loss.

Table 2: Primary outcome variables.

\begin{tabular}{|c|c|c|c|}
\hline Variables & Group A & Group B & $\begin{array}{l}P \\
\text { value }\end{array}$ \\
\hline \multicolumn{4}{|c|}{ Maternal vitals } \\
\hline \multicolumn{4}{|c|}{ Pulse rate/min Mean (SD) } \\
\hline Pre-delivery & $79.84 \pm 4.98$ & $80.32 \pm 6.07$ & \\
\hline Post delivery & $88.10 \pm 5.78$ & $82.24 \pm 6.45$ & \\
\hline $\mathrm{P}$ value & $(0.0001)$ & $(0.128)$ & \\
\hline \multicolumn{4}{|c|}{ Blood pressure mmHg, Mean (SD) } \\
\hline Pre-delivery & $86.12 \pm 5.76$ & $85.36 \pm 5.42$ & \\
\hline Post delivery & $88.31 \pm 5.58$ & $83.92 \pm 6.08$ & \\
\hline $\mathrm{P}$ value & $(0.056)$ & $0.214)$ & \\
\hline $\begin{array}{l}\text { Amount of } \\
\text { blood loss } \\
\text { (ml) Mean } \\
\text { (SD) }\end{array}$ & $360.5(88.01)$ & $290.6(40.01)$ & 0.0001 \\
\hline $\begin{array}{l}* \text { PPBL } \\
>500 \mathrm{ml}, \mathbf{N}(\%\end{array}$ & $12(12 \%)$ & 0 & \\
\hline \multicolumn{4}{|c|}{ Subdivisions of amount of blood loss (ml), N (\%) } \\
\hline$\leq 200$ & $2(2 \%)$ & $18(18 \%)$ & \\
\hline $201 \leq 300$ & $34(34 \%)$ & $40(40 \%)$ & \\
\hline $301 \leq 400$ & $40(40 \%)$ & $36(36 \%)$ & \\
\hline $401 \leq 500$ & $12(12 \%)$ & $6(6 \%)$ & \\
\hline$>500$ & $12(12 \%)$ & 0 & \\
\hline $\begin{array}{l}\text { Duration of } \\
\text { third stage } \\
\text { (min), mean } \\
\text { (SD) }\end{array}$ & $13.46 \pm 8.73$ & $5.32 \pm 3.05$ & 0.0001 \\
\hline \multicolumn{4}{|c|}{ Subdivisions of third stage (min), N (\%) } \\
\hline$\leq 5$ & $22(22 \%)$ & $66(66 \%)$ & \\
\hline$\overline{6} \leq 10$ & $26(26 \%)$ & $24(24 \%)$ & \\
\hline$>10$ & $52(52 \%)$ & $10(10 \%)$ & \\
\hline $\begin{array}{l}\text { Fall in } \\
\text { hemoglobin } \\
\text { level > 2g/dl }\end{array}$ & $20(20 \%)$ & $6(6 \%)$ & 0.01 \\
\hline
\end{tabular}

Average fetal weight was also comparable between the two groups and not significantly different although it is 
an independent variable influencing amount of blood loss as higher the fetal weight more the distention of uterus and greater the chances of atony, but in present study this was not significant.

Among the outcome variables (Table 2). Comparing the vitals, there was statistically significant difference in pre and post-delivery mean pulse rate in group A ( $\mathrm{P}-0.0001)$ while not in group $\mathrm{B}$ which could be attributed to greater amount of blood loss in group A, however there was no significant difference in pre and post-delivery mean blood pressure in any group.

Duration of second stage of labour was almost same in the two groups (Table 1) however, the mean duration of third stage of labour (Table 2) was shorter, 5.32( \pm 3.05$)$ minutes vs $13.46( \pm 8.73)$ minutes in the active management group, which was statistically significant $(\mathrm{P}=0.001)$.

This was similar to studies done by Jangsten E et al, Maryam K et al, Dogukan Y et al, Niven RB. ${ }^{18-21} 22 \%$ cases in group A had mean duration of third stage of labour $\leq 5 \mathrm{mins}$ compared to $66 \%$ in group B whereas, in group A i.e., expectant management $53 \%$ of patients had mean duration of third stage $\geq 11$ min compared to $10 \%$ in group B. Mean blood loss in group A was around $360.5 \mathrm{ml}$ as compared to group B which was $290.6 \mathrm{ml}$. The difference was statistically significant (P-0.0001). Twelve patients in group A had more than $500 \mathrm{ml}$ blood loss and developed PPH and required transfusion as well as uterotonics, while none in group B. However, none of the patients developed severe PPH.
Transfusions were done even when clinical and haematological variables suggested significant blood loss or when the patient displayed symptoms and signs of hypoxemia while the haemoglobin concentration was lower than $8 \mathrm{~g} / \mathrm{dl}$ at the end of the $24^{\text {th }}$ postpartum hour. Comparing secondary outcomes (Table 3), 6 patients in group A had retained placenta, out of which three needed Manual removal. Uterotonics were needed to be added in 18 patients in group A which included the patients who developed retained placenta. Additional uterotonic in form of prostaglandin analogue (misoprostol 800ug) was required in only one case in group B where the blood loss was more than $450 \mathrm{ml}$.

Table 3: Secondary outcome variables.

\begin{tabular}{|l|l|l|}
\hline Retained placenta N (\%) & $6(6)$ & 0 \\
\hline $\begin{array}{l}\text { Need to add uterotonic } \\
\text { agent N (\%) }\end{array}$ & $18(18)$ & 1 \\
\hline $\begin{array}{l}\text { Manual removal of placenta } \\
\text { N }(\%)\end{array}$ & $3(3)$ & 0 \\
\hline $\begin{array}{l}\text { Need for blood transfusion } \\
\text { N }(\%)\end{array}$ & 16 & 2 \\
\hline
\end{tabular}

Haemoglobin level 24 hours post delivery fell by more than $2 \mathrm{~g} / \mathrm{dl}$ in 20 patients in group A as compared to only $6 \%$ in group $\mathrm{B}$ ( $\mathrm{P}$ value 0.01 ). 16 patients in group $\mathrm{A}$ required blood transfusion which included the cases of retained placenta and those who developed PPH due to uterine atony. No significant adverse effects were noticed. Shows comparison with other studies (Table 4).

Table 4: Comparison with other studies.

\begin{tabular}{|c|c|c|c|c|}
\hline \multirow{2}{*}{$\begin{array}{l}\text { Parameters } \\
\text { Study }\end{array}$} & \multicolumn{2}{|c|}{ Mean Duration of third stage of labour (min) } & \multicolumn{2}{|c|}{ Mean post-partum blood loss in third stage (ml } \\
\hline & $\begin{array}{l}\text { Active } \\
\text { management }\end{array}$ & Expectant management & $\begin{array}{l}\text { Active } \\
\text { management }\end{array}$ & $\begin{array}{l}\text { Expectant } \\
\text { management }\end{array}$ \\
\hline Dogukan $Y$ et $\mathrm{al}^{20}$ & $4.11(2.32)$ & $9.26(4.59)$ & -- & -- \\
\hline Jangsten $\mathrm{E}$ et $\mathrm{al}^{18}$ & $14.6(15.8)$ & $16.2(14.78)$ & $535(414.5)$ & $680(486.7)$ \\
\hline Maryam $\mathrm{K}$ et al ${ }^{19}$ & $4.69(5.5)$ & $6.34(5.03)$ & $216.93(165.16)$ & $232.12(150.35)$ \\
\hline Present study & $5.32(3.05)$ & $13.46(8.73)$ & $290.6(40.01)$ & $360.5(88.01)$ \\
\hline Niven $R^{21}$ & -- & -- & $82.5(23.73)$ & $156.4(67.47)$ \\
\hline Rukhsana $\mathrm{K}$ et al ${ }^{22}$ & -- & -- & $72.5(36.83)$ & $177.4(59.65)$ \\
\hline
\end{tabular}

\section{DISCUSSION}

A prolonged third stage of labour is often associated with increased risk of maternal morbidity and mortality due to PPH. Present study involved comparison of expectant and active management for third stage with prompt interventions when needed to treat $\mathrm{PPH}$ and authors found significant reduction in amount of blood loss and duration of third stage of labour with active management. $80 \%$ patients in group B had third stage of labour less than 10 min while in group A $52 \%$ patients had third stage more than $10 \mathrm{~min}$. $58 \%$ patients in group B had blood loss less than $300 \mathrm{ml}$ as compared to group A $(36 \%)$.

Jangsten et al, in their randomized control trial have demonstrated that there was only $10 \%$ blood loss in woman who received AMTSL as compared to $16.8 \%$ blood loss in the woman who didn't ( $p$ value of $<0.001$ ). Also, multiple logistic regressions resulted that for every 
five minutes duration before delivery of the placenta, bleeding increased by $40 \mathrm{ml}$, thus supporting that longer the duration of third stage, greater the blood loss.

Two research papers with the difference between them of more than ten years agreed with the present study result; Karim et al, Nothnagle and Taylor demonstrated that AMTSL was superior on the expectant management with statistically significant decrease in the blood loss and shorter duration of 3rd stage of labour. ${ }^{22,23}$ Authors included all three components of AMTSL, although conflicting results with regard to the effect of early or late cord clamping for the mother and neonate have recently been published. ${ }^{24} \mathrm{McD}$ onald et al, analyzed the timing of umbilical cord clamping in a Cochrane review of 11 trials and 2898 patients. $^{25}$ Their conclusion was that delaying umbilical cord clamping had no effect on the amount of blood loss or severe postpartum hemorrhage rates, but resulted in higher neonatal hemoglobin levels and increased rates of neonatal jaundice. Sheldon et al, in their systematic assessment have documented that the significance of CCT is only if the uterotonic agents are not available or if oxytocin is given intramuscularly. ${ }^{26}$ Similarly, Gulmezoglu et al, compared active management performed with and without controlled cord traction in a large WHO multi-center trial and only showed a slight increased risk of severe postpartum hemorrhage in cases without controlled cord traction and concluded that the main component of active management was the use of uterotonic. ${ }^{27}$

A Cochrane database meta-analysis by Begley et al, showed that although active management reduced mean blood loss and postpartum hemorrhage $(>500 \mathrm{cc})$, there was no statistically significant reduction in severe postpartum hemorrhage $(>1000 \mathrm{cc})$ for women at low risk for bleeding as well as in mean duration of third stage of labour, which was in contrast to present study. ${ }^{28}$ The secondary outcomes in present study showed increased need for blood transfusions and adding uterotonics in expectant management group. Present study was conducted on a low risk population is not without limitations. The differences in the findings may be due to small sample size. In our country, where the incidence of anaemia during pregnancy is high, even small amount of blood loss may be of great clinical significance thus favouring routine practice of active management. Reducing the duration of third stage of labour can prevent uterine atony and PPH. However, delayed cord clamping (performed after 1 to 3 minutes after birth) is still recommended for all births to reduce infant anaemiawhile beginning essential newborn care at the same time. The WHO and professional bodies recommend active management of the third stage of labour (AMTSL) for all vaginal births in order to prevent PPH. This involves prophylactic administration of uterotonic medicines before delivery of the placenta in addition to other nonpharmacological interventions, such as late cord clamping and controlled cord traction of the umbilical cord (in settings where skilled birth attendants are available). Although AMTSL reduces postpartum blood loss, about $3 \%$ to $16.5 \%$ of women will still go on to experience $\mathrm{PPH}$ and will require treatment. ${ }^{29}$

\section{CONCLUSION}

The active management of the third stage of labour decreased post-partum blood loss as well as duration of third stage of labour as compared with expectant management. Though the contribution and effectiveness of individual components is still being studied but use of uterotonics definitely seems to be the most important factor. Expectant management should only be used when all other methods are contraindicated or uterotonics are not available. It is reasonable to advocate the active management of third stage of labour as the reduction of blood loss has a much greater impact on women's health in low income countries compared with high income countries. While substantial progress has been made towards improving on the existing interventions for managing PPH, the burden of PPH still persists because there is no "silver bullet" for either the prevention or treatment of PPH.

\section{Funding: No funding sources \\ Conflict of interest: None declared \\ Ethical approval: Not required}

\section{REFERENCES}

1. Alkema L, Chou D, Hogan D, Zhang S, Moller AB, Gemmill A, et al. Global, regional, and national levels and trends in maternal mortality between 1990 and 2015, with scenario-based projections to 2030: a systematic analysis by the UN Maternal Mortality Estimation Inter-Agency Group. Lancet. 2016;387(10017):462-74.

2. Khan KS, Wojdyla D, Say L, Gülmezoglu AM, Van Look PF. WHO analysis of causes of maternal death: a systematic review. Lancet. 2006;367(9516):106674.

3. Haeri S, Dildy III GA. Maternal mortality from hemorrhage. Seminars Perinatol. 2012;36(1):48-55.

4. Miller S, Lester F, Hensleigh P. Central European University. Prevention and Treatment of Postpartum Hemorrhage: New Advances for Low-Resource Settings. J Midwifery Women's Health. 2004;49(4):283-92.

5. WHO/MCH. Prevention and Management of PostPartum Hemorrhage. Report of technical working group, July 1989. WHO/MCH/90.7, Geneva 1990.

6. El-Refaey H, Rodeck C. Post-partum haemorrhage: definitions, medical and surgical management. A time for change. Brit Medical Bulletin. 2003;67(1):205-17.

7. WHO Recommendations for the Prevention of Postpartum Hemorrhage. 2012 sec1:4; page 2.

8. Prendiville WJ, Elbourne D, McDonald SJ. Active versus expectant management in the third stage of 
labour. Cochrane Database of systematic reviews. 2000(3).

9. WHO DoMPS. WHO Recommendations for the prevention of postpartum haemorrhage. Geneva: World Health Organization, 2007.

10. Harris T. An explanation for the third stage practice variation: the theory of contingent decision-making. In Normal labour and birth: $3^{\text {rd }}$ Research Conference 7-9 June 2006 at Grangeover-Sands, Cumbria, England. 2006.

11. Winter C, Macfarlane A, Deneux-Tharaux C, Zhang WH, Alexander S, Brocklehurst P, et al. Variations in policies for management of the third stage of labour and the immediate management of postpartum haemorrhage in Europe. BJOG: Int $\mathrm{J}$ Obstet Gynaecol. 2007;114(7):845-54.

12. Lalonde A, Daviss BA, Acosta A, Herschderfer K. Postpartum hemorrhage today: ICM/FIGO initiative 2004-2006. Int J Gynecol Obstet. 2006;94(3):243-53.

13. Joint Statement. Joint statement: management of the third stage of labour to prevent post-partum haemorrhage. J Midwifery Womens Health. 2004;49:76-7.

14. WHO. Recommendations for the prevention of postpartum haemorrhage department of making pregnancy safer. Geneva: WHO, 2006.

15. Festin MR, Lumbiganon P, Tolosa JE, Finney KA, Ba-Thike K, Chipato T, et al. International survey on variations in practice of the management of the third stage of labour. Bull World Health Organ. 2003;81:286-91.

16. Kodkany BS, Derman RJ. A textbook of postpartum haemorrhage: a comprehensive guide to evaluation, management and surgical intervention; special FOGSI ed. Jaypee brothers. 2006;1(4):35-41.

17. Patel A, Goudar SS, Geller SE, Kodkany BS, Edlavitch SA, Wagh K, et al. Drape estimation versus visual assessment for estimating postpartum haemorrhage. Int J Gynaecol Obstet. 2006;93:220-4.

18. Jangsten E, Mattsson LA, Lyckestam I, Hellström AL, Berg M. A comparison of active management and expectant management of the third stage of labour: a Swedish randomised controlled trial. BJOG: Int J Obstet Gynaecol. 2011;118(3):362-9.

19. Maryam K, Mohsen F, Zahra M, Narges SA. Comparison of active and expectant management on the duration of the third stage of labour and the amount of blood loss during the third and fourth stages of labour: a randomised controlled trial. Midwifery. 2010;26(2):241-5.
20. Dogukan Y, Sefik EO, Ali E, Elif CE, Derya UH, Olgu B, Kerem DS, et al. Comparison of active vs. expectant management of the third stage of labor in women with low risk of postpartum hemorrhage: a randomized controlled trial. Polish Gynecol. 2016;87(5):399-404.

21. Niven RB. Effect of Active versus Expectant Nursing Management of Third Stage of Labour on Post-Partum Hemorrhage. IOSR-JNHS. 2017;6(1):89-94.

22. Karim R, Pervaiz F, Muhammad MF. Comparison of active versus expectant management of third stage of labour. J Postgrad Med Inst. 2015;29(1):14-7.

23. Nothnagle M, Taylor S J. Should Active Management of the Third Stage of Labour Be Routine? Am Fam Physician. 2003;67(10):2119-20.

24. Hutton EK, Hassan ES. Late vs. early clamping of the umbilical cord in full-term neonates: systematic review and meta-analysis of controlled trials. JAMA. 2007;297:1241-52.

25. McDonald SJ, Middleton P. Effect of timing of umbilical cord clamping of term infants on maternal and neonatal outcomes. Cochrane Database Syst Rev. 2008;2(2):CD004074.

26. Sheldon RW, Durocher J, Winikoff B, Blun J, Trissell J. How effective are the components of active management of the third stage of labour? BMC Preg Childbirth. 2013;13:46.

27. Gülmezoglu AM, Lumbiganon P, Landoulsi S, Widmer M, Abdel-Aleem H, Festin M, et al. Active management of the third stage of labour with and without controlled cord traction: a randomised, controlled, non-inferiority trial. Lancet. 2012;379(9827):1721-7.

28. Begley CM, Gyte GML, Devane D, McGuire W, Weeks A. Active versus expectant management for women in the third stage of labour. Cochrane Database Syst Rev. 2015;(3):CD007412.

29. PATH. Postpartum hemorrhage prevention and treatment website. 2011. Available at: http://www.pphprevention.org/pph.php.

Cite this article as: Chandnani KA, Sharma DD. Third stage of labour: expectant versus active management-a comparative study in local low risk population. Int J Reprod Contracept Obstet Gynecol 2019;8:641-6. 